\title{
Association of vitamin $D$ receptor gene polymorphism with the occurrence of low bone density, osteopenia, and osteoporosis in patients with type 2 diabetes
}

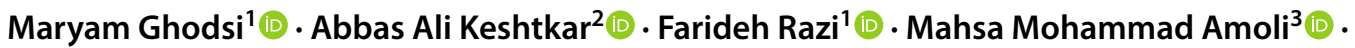

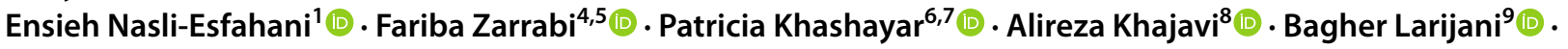 \\ Mohamad Reza Mohajeri-Tehrani ${ }^{9}$ (1)
}

Received: 25 May 2021 / Accepted: 31 July 2021 / Published online: 23 August 2021

(c) Springer Nature Switzerland AG 2021

\begin{abstract}
Purpose This study aims to analyze the association between VDR gene polymorphism and the occurrence of "low bone density (LBD)/osteopenia/osteoporosis" or LBDOO in type 2 diabetes (T2D) patients among a clustered population in northwest of Iran. The studied VDR gene polymorphism included ApaI (rs7975232), BsmI (rs1544410), FokI (rs2228570), EcoRV (rs4516035) and, TaqI (rs731236).

Methods In this population-based cross-sectional study, patients with T2D were identified within a group of 1266 participants based on self-report of diabetes, history of diabetes medication, and recorded laboratory data. Separately for each polymorphism and gender, crude and adjusted (age, BMI) odds ratios (ORs) were calculated for participants with T2D through logistic regression analysis.

Results The prevalence of T2D was $16.41 \%$ in people residing in the city of Sanandaj in 2011. Of the participants with T2D, $13.92 \%$ and $81.29 \%$ had osteoporosis and vitamin D deficiency, respectively. In women, the $t$ genotype of the TaqI gene significantly decreased the risk of LBDOO versus the $T t$ genotype, after adjusting for BMI and age (adjusted OR:0.18, $\left.\mathrm{CI}_{95 \%}: 0.03-0.97\right)$. Conversely, the $E E$ genotype of the $E c o R V$ gene enhanced the risk of LBDOO versus the Ee genotype (adjusted OR:7.64, $\mathrm{CI}_{95 \%}: 2.03-28.72$ ).

Conclusion The polymorphism of both TaqI and EcoRV genes was associated with the risk of LBDOO in women with T2D. This is the first time a study has highlighted this effect for the polymorphism of the $E c o R V$ gene; we believe that this study would serve as a basis for future studies.
\end{abstract}

Keywords VDR polymorphism · Type 2 diabetes $\cdot$ Osteoporosis $\cdot$ Cluster random sampling $\cdot$ Logistic regression $\cdot$ Effect size

\section{Introduction}

Diabetes, osteoporosis, and vitamin D deficiency are common [1-3] and interrelated [4, 5], globally. Osteoporosis and type 2 diabetes (T2D) are among the major risk factors of deaths in any population [6]. The impact of genetic and environmental factors on these outcomes has been previously demonstrated [7-9].

Mohamad Reza Mohajeri-Tehrani

mrmohajeri@tums.ac.ir

Extended author information available on the last page of the article
Almost $50 \%$ of the population worldwide is affected by vitamin D insufficiency [2]. The function of vitamin D is mediated through the vitamin D receptor (VDR) [10]. Osteoporosis is verified as a hereditary illness with published data showing that $60-80 \%$ of bone density is under genetic control [11]. The VDR coding gene is one of the most studied genes as a major locus with an impact on bone density [12-14]. Different VDR genes polymorphism show dissimilar effects on the risk of osteoporosis [15]. The most studied the VDR polymorphism are ApaI (rs7975232), BsmI (rs1544410), FokI (rs2228570) and, TaqI (rs731236) [16].

Additionally, vitamin D has a well-established role in regulating the normal function of the pancreatic beta-cells and is associated with both types of diabetes $[17,18]$. There is a 
relationship between the presence of vitamin D deficiency and the incidence [19], control [20,21], complications, and mortality due to diabetes [22, 23]. During the last decade, multiple studies have demonstrated associations between T2D and polymorphism in the VDR gene (BsmI [24-27], EcoRV [16], FokI [24, 25, 27], and TaqI [26]); however, studies negating such associations could also be found [28, 29].

Since the reported results of VDR single nucleotide polymorphism (SNP) may be population-specific, it is necessary to study genetic polymorphism in different ethnic groups separately. Among different polymorphisms of the VDR genes, ApaI (rs7975232), BsmI (rs1544410), EcoRV (rs4516035), FokI (rs2228570), and TaqI (rs731236) are assumed to alter the activity of the receptor, and susceptibility to T2D [16]. This study aims to analyze the association between VDR gene polymorphism (ApaI, BsmI, EcoRV, FokI and, TaqI) and occurrence of "LBD/osteopenia/osteoporosis" or LBDOO in a population with type 2 diabetes participated in phase III of the Iranian Multi-Center Osteoporosis Study (IMOS) study in the city of Sanandaj, Iran [30]. Sanandaj is the capital of Kurdistan Province in Iran (latitude $35.2458^{\circ} \mathrm{N}$, longitudes $47.0092^{\circ} \mathrm{E}$, the population in 2011: $311,446,000$ ).

\section{Material and methods}

\section{Participants}

The current study protocol was accepted by the ethics committee of the Endocrinology and Metabolism Research Institute (EMRI) in 2015. We used secondary data from phase III of the IMOS study in Sanandaj city. The IMOS study was performed by researchers at the EMRI in 2010 in the cities of Arak and Sanandaj; the genetic study on the VDR genes was only performed on city samples from the Sanandaj [30]. The primary recruited participants were selected through a randomized clustered sampling method [30].

\section{Inclusion criteria}

Participants in the IMOS study were healthy subjects over 20 years old [4]. The present study included those participants from the Sanandaj city who were aged 26 years and more and were considered to be afflicted with T2D. To achieve a realistic estimation for individuals with T2D, we based our methodology upon similar studies such as those conducted on the NHANES population [31, 32]. Selfreported data on the diagnosis of diabetes or insulin usage have agreeable applications in the identification of individuals with diabetes [33]. Regardless of the results of the laboratory test, we considered participants with a self-report of diabetes as patients with T2D, unless they met the exclusion criteria described for the detection of T1D patients. Among participant records in which there was no positive history of diabetes, those with fast blood sugar (FBS) $\geq 126 \mathrm{mg} / \mathrm{dl}$ or glycated hemoglobin $(\mathrm{A} 1 \mathrm{C}) \geq 6.5 \%$ were assumed as undiagnosed T2D unless they met the exclusion criteria described for the detection of T1D patients [31,32].

\section{Exclusion criteria}

The data from records of principal participants were excluded from our study when there was no mention of diabetes in the questionnaire and laboratory data for FBS and A1C also excluded diabetes. Other exclusion criteria were insulin usage in participants despite the absence of other oral hypoglycemic agents, as well as identification of type 1 diabetes.

\section{Bone status classification}

All participants in the initial study were invited to perform bone mineral densitometry (BMD). BMD measurements at three sites (the lumbar spine (12-L4), hip, and femoral neck) were performed using Dual-Energy X-ray Absorptiometry (Norland XR46) [30]. Considering the age, gender, and menopausal status, we assessed the data from the BMD measurements $\left(\mathrm{g} / \mathrm{cm}^{2}\right)$ based on the criteria of the World Health Organization (WHO) [34]. The DEXA variables were expressed by T-score and Z-score. Post-menopausal women and men over 50 years were divided into normal, osteopenic, and osteoporotic based on their T-score at any site. As for premenopausal women and younger men, Z-score at any site was used to detect individuals with low and normal bone mass [35]. The recruited participants were divided into two groups: normal and low. It means that the second group included participants who were diagnosed with either low bone density (LBD), osteopenia, or osteoporosis at any of the three mentioned sites.

\section{Vitamin D classification}

Considering Endocrine Society Clinical Practice Guideline [36], vitamin D deficiency was defined as 25-hydroxyvitamin D below $20 \mathrm{ng} / \mathrm{ml}(50 \mathrm{nmol} / \mathrm{l})$.

\section{Genotyping}

Genomic DNA was isolated from peripheral blood leukocytes, and DNA extraction was performed using the standard phenol-chloroform method [30]. Five sites VDR SNPs including FokI (rs2228570), TaqI (rs731236), ApaI (rs7975232), BsmI (rs1544410), and EcoRV (rs4516035) were analyzed using Taq-Man 5'-exonuclease SNP assay 
(Applied Biosystems, FosteCity, CA, USA) by allelic discrimination method with the ABI 7300 Real-Time PCR System (Applied Biosystems, 850 Lincoln Centre Drive, Foster City, California 94404, USA). Negative controls were included to ensure the accuracy of genotyping. Thermal cycling conditions and data analysis were according to the standard manufacturer's instructions [4].

The nomenclature of the genotypes was as follows; the restriction endonucleases of ApaI (allele A/a), BsmI (allele $B / b$ ), EcoRV (allele E/e), FokI (allele F/f), and TaqI (allele $T / t)$ are recognized as allelic variants of the genes encoding VDR.

\section{Statistical analysis}

Considering the SAMPLE guideline [37], in the case of continuous variables with normal distribution, either the data were summarized with mean and standard deviations (SD), or the data were reported with median and interquartile range. Categorical variables were expressed as percentages. The normality assumption was checked using statistical tests (Kolmogorov-Smirnov/Shapiro-Wilk test) and graphical assessments (histograms, Q-Q plots, and box plots). Evaluating relationships between the main outcomes and explanatory variables (bivariate analysis), the following tests were performed: Chi-squared test (Pearson/Fisher test), t-test, Mann-Whitney U test, and Pearson/Spearman correlation coefficient.

Logistic regression analysis was applied to quantify the correlation between the LBDOO status and VDR gene polymorphism. The most common haplotype was used as the reference for each type of VDR gene polymorphism. Separately for each gender and polymorphism, crude and adjusted (age, BMI) odds ratios (ORs) were calculated by logistic regression analysis. All analyses were performed at a significance level of 5\% and $95 \%$ Confidence Interval $\left(\mathrm{CI}_{95 \%}\right)$ were calculated for each relevant parameter. We used version 11 of the Stata software to analyze the data.

\section{Results}

Finally, 165 individuals met the inclusion criteria in the following order: In the first step, 261 of 1266 (20.62\%) records were omitted because of missing necessary data for defining diabetes status according to the exclusion criteria. Then, of the 1005 remain, participants who received insulin and were under 25 years of age were excluded from the study by diagnosing type 1 diabetes $(\mathrm{N}=5,0.49 \%)$. Final participants were selected as potential cases affected by T2D based on their self-report of diabetes, history of diabetes medication, and recorded laboratory data $(\mathrm{N}=165,16.41 \%)$. Referring to the primary questionnaire, the self-report of T2D was $27.88 \%$ (46/165) among participants. If we would consider the existence of either insulin or the oral hypoglycemic agents in the list of medications used by participants as a sign of having diabetes, then it should be said that $72.12 \%(118 / 165)$ of diabetic patients have been treated with medication for diabetes. Some T2D participants did not attend the BMD clinic, which led to missing BMD records $(n=7,4.24 \%)$.

The mean age of our study participants was 50 years $(\mathrm{N}=165)$, and most of them were women $(61.82 \%)$. The demographic and laboratory data for participants with T2D are illustrated in Table 1. Considering the WHO osteoporosis criteria [34], 13.92\% (22/158) of T2D participants had osteoporosis in at least one of the three primary sites; the occurrence of osteoporosis was higher $(P=0.043)$ in women than men $[15.15 \%(15 / 99)$ vs. $11.86 \%$ (7/59); respectively]. The occurrence of vitamin D deficiency was $81.29 \%$ (126/155) among participants based on the Endocrine Society Clinical Practice Guideline [36]. There was no significant difference in laboratory data between the two genders.

Table 2 shows the frequency of the VDR gene's polymorphism in participants with T2D according to gender. There was no significant difference between the two genders in the frequency of each of the studied VDR genes polymorphism. The most common genotypes for ApaI, BsmI, EcoRV, FokI, and TaqI were Aa (46.36\%), Bb (65.13\%), EE (43.71\%), FF (52.29\%), and $T t(46.71 \%)$, respectively.

In participants with $\mathrm{T} 2 \mathrm{D}$, the association of the VDR gene's polymorphism (ApaI, BsmI, FokI, EcoRV, and TaqI) with osteoporosis is illustrated in Table 3. Model 1 and model 2 depict the crude association and the association adjusted for BMI and age, respectively. In women, the $t t$ genotype decreased the risk of LBDOO versus the Tt genotype, after adjusting for BMI and age (adjusted OR:0.18, $\mathrm{CI}_{95 \%}$ : 0.03-0.97). Conversely, the $E E$ genotype increased the risk of LBDOO versus the $E e$ genotype in women, after adjusting for BMI and age (adjusted OR:7.64, $\mathrm{CI}_{95 \%}$ : 2.03-28.72).

\section{Sensitivity analysis}

Among 165 selected participants, only 46 (27.88\%) mentioned being diabetic in their primary questionnaire. It was impossible to perform the same logistic analysis due to the many empty cells in this group. We separately repeated the association analysis in another subgroup of participants in which $\mathrm{A} 1 \mathrm{C} \geq 6.4 \%$ and $\mathrm{FBS} \geq 3.9 \mathrm{mmol} / \mathrm{l}(126 \mathrm{mg} / \mathrm{dl})$. The sensitivity analysis is illustrated in Table 4 . Regarding the associations of $E c o R V$ polymorphism, the sensitivity analysis was consistent with the primary analysis. 
Table 1 Demographic and laboratory data of participants with type 2 diabetes enrolled in phase III of IMOS study in the city of Sanandaj according to gender

\begin{tabular}{|c|c|c|c|c|}
\hline Variables & $\begin{array}{l}\text { Men } \\
\text { Mean (SD) }\end{array}$ & $\begin{array}{l}\text { Women } \\
\text { Mean (SD) }\end{array}$ & $\begin{array}{l}\text { Total } \\
\text { Mean (SD) }\end{array}$ & $P$ value \\
\hline Age (years) & $51.02(12.85)$ & $50.76(10.07)$ & $50.86(11.17)$ & $0.889^{\mathrm{a}}$ \\
\hline \multirow[t]{2}{*}{ BMI $\left(\mathrm{kg} / \mathrm{m}^{2}\right)$} & $27.63(3.85)$ & $30.46(4.26)$ & $29.40(4.32)$ & $\mathbf{0 . 0 0 0}^{\mathrm{a}}$ \\
\hline & $\operatorname{Mdn}\left(Q_{1}, Q_{3}\right)$ & $\operatorname{Mdn}\left(Q_{1}, Q_{3}\right)$ & $\operatorname{Mdn}\left(Q_{1}, Q_{3}\right)$ & \\
\hline FBS (mg/dl) & $142(126,171)$ & $132(111,161)$ & $137(118,163)$ & $0.129^{\mathrm{b}}$ \\
\hline $\mathrm{A} 1 \mathrm{C}(\%)$ & $6.3(5.8,7.1)$ & $6.6(6.1,7.6)$ & $7.6(6.0,7.5)$ & $0.062^{\mathrm{b}}$ \\
\hline \multirow[t]{2}{*}{ Vitamin D (nmol/l) } & $25.9(18.8,40.3)$ & $22.6(13.0,44.3)$ & $25.1(13.6,40.7)$ & $0.193^{\mathrm{b}}$ \\
\hline & $\mathrm{N}(\%)$ & $\mathrm{N}(\%)$ & $\mathrm{N}(\%)$ & \\
\hline Gender & $63(38.18)$ & $102(61.82)$ & $165(100)$ & $\mathbf{0 . 0 0 0}{ }^{c}$ \\
\hline \multicolumn{5}{|l|}{ Serum vitamin-D (nmol/l) } \\
\hline Deficient $(<50)$ & $49(85.96)$ & $77(78.57)$ & $126(81.29)$ & $0.316^{\mathrm{c}}$ \\
\hline Insufficient (50-72.5) & $4(7.02)$ & $15(15.31)$ & $19(12.26)$ & \\
\hline Sufficient to optimal $(\geq 72.5)$ & $4(7.02)$ & $6(6.12)$ & $10(6.45)$ & \\
\hline Total & $57(100)$ & $98(100)$ & $155(100)$ & \\
\hline \multicolumn{5}{|l|}{ Bone density groups ${ }^{\mathrm{e}}$} \\
\hline Normal & $23(38.98)$ & $55(55.56)$ & $78(49.37)$ & $\mathbf{0 . 0 4 3}^{\mathrm{c}}$ \\
\hline LBD/Osteopenia & $29(49.15)$ & $29(29.29)$ & $58(36.71)$ & \\
\hline Osteoporosis & 7 (11.86) & $15(15.15)$ & $22(13.92)$ & \\
\hline Total & $59(100)$ & $99(100)$ & $158(100)$ & \\
\hline \multicolumn{5}{|l|}{ Bone density status ${ }^{\mathrm{f}}$} \\
\hline Normal & $23(38.98)$ & $55(55.56)$ & $78(49.37)$ & $0.044^{\mathrm{c}}$ \\
\hline LBDOO & $36(61.02)$ & $44(44.44)$ & $80(50.63)$ & \\
\hline Total & $59(100)$ & $99(100)$ & $158(100)$ & \\
\hline \multicolumn{5}{|l|}{ 10-years age groups (year) } \\
\hline $20-29$ & $4(6.78)$ & $0(0.00)$ & $4(2.53)$ & $0.055^{\mathrm{d}}$ \\
\hline $30-39$ & $10(16.95)$ & $14(14.14)$ & $24(15.19)$ & \\
\hline $40-49$ & $9(15.25)$ & $31(31.31)$ & $40(25.32)$ & \\
\hline $50-59$ & $21(35.59)$ & $37(37.37)$ & $58(36.71)$ & \\
\hline $60-69$ & $10(16.95)$ & $14(14.14)$ & $24(15.19)$ & \\
\hline$>70$ & $5(8.47)$ & $3(3.03)$ & $8(5.06)$ & \\
\hline Total & $59(100)$ & $99(100)$ & $158(100)$ & \\
\hline
\end{tabular}

LBDOO:“ low bone density (LBD)/osteopenia/osteoporosis”; Variables with normal distribution describe as mean (SD) and the skewed ones as $\operatorname{Mdn}(\mathrm{Q} 1, \mathrm{Q} 3) ; \mathrm{Mdn}=$ median; $\mathrm{Q}_{1}=25$ th percentile; $\mathrm{Q}_{3}=75$ th percentile. $P$ Value $<.05$ assumed significant and bolded

${ }^{a}$ Based on T-test, ${ }^{b}$ based on Mann-Whitney U test, ${ }^{\mathrm{c}}$ based on Pearson Chi2 test; ${ }^{\mathrm{d}}$ based on Fisher's exact test; ${ }^{\mathrm{e}}$ based on the criteria of the World Health Organization (WHO) [34]; ${ }^{\mathrm{f}}$ The specific definition and classification of the current study

\section{Discussion}

This population-based cross-sectional study demonstrated that the prevalence of T2D was $16.41 \%$ among individuals residing in the city of Sanandaj in winter 2011 (Table 1). Our results are nearly consistent with the WHO reports, in which the stated average prevalence of diabetes in the adult population was $13.7 \%$ in the Eastern Mediterranean Region (EMRO) in 2014 [38]. There was a low rate of diabetes selfreport among our study population $(27.88 \%)$. This can be explained by the fact that up to $50 \%$ of diabetics are unaware of their disease [39]. Moreover, in the IMOS study questionnaire, participants were merely asked to list their disease. They were not asked about diabetes, specifically. $\square$

The results of this study indicate that $13.92 \%$ and $36.71 \%$ of participants with T2D aged between 26 and 83 years had osteoporosis and LBD/Osteopenia, respectively (Table 1). In 2013, a meta-analysis reported that among Iran's general population aged $>30$ years $17 \%$ and $35 \%$ have osteoporosis and osteopenia, respectively [40]. As age is one of the most important risk factors for bone loss, we hold the wide age range in the participants of the present study responsible 
Table 2 Frequency of VDR gene's polymorphism (ApaI, BsmI, EcoRV, FokI, and TaqI) in women versus men in participants with type 2 diabetes

\begin{tabular}{|c|c|c|c|c|}
\hline Gene & Polymorphism & Male & Female & $P$ value \\
\hline \multirow[t]{4}{*}{ ApaI } & $\mathrm{Aa}$ & $25(44.46)$ & $45(47.37)$ & $70(46.36) 0.894^{\mathrm{a}}$ \\
\hline & $\mathrm{AA}$ & $21(37.50)$ & $32(33.68)$ & $53(35.10)$ \\
\hline & aa & $10(17.86)$ & $18(18.95)$ & $28(18.54)$ \\
\hline & Total & $56(100)$ & $95(100)$ & $151(100)$ \\
\hline \multirow[t]{4}{*}{ BsmI } & $\mathrm{Bb}$ & $40(70.18)$ & $59(62.11)$ & $99(65.13) 0.544^{b}$ \\
\hline & BB & $14(24.56)$ & $31(32.63)$ & $46(29.61)$ \\
\hline & $\mathrm{bb}$ & $3(5.26)$ & $5(5.26)$ & $8(5.26)$ \\
\hline & Total & $57(100)$ & $95(100)$ & $152(100)$ \\
\hline \multirow[t]{4}{*}{ EcoRV } & $\mathrm{EE}$ & $25(44.64)$ & $41(43.16)$ & $66(43.71) 0.928^{\mathrm{a}}$ \\
\hline & $\mathrm{Ee}$ & $24(42.86)$ & $40(42.11)$ & $64(42.38)$ \\
\hline & ee & $7(12.50)$ & $14(14.74)$ & $21(13.91)$ \\
\hline & Total & $56(100)$ & $95(100)$ & $151(100)$ \\
\hline \multirow[t]{4}{*}{ FokI } & FF & $29(50.88)$ & $51(53.13)$ & $80(52.29) 0.603^{b}$ \\
\hline & $\mathrm{Ff}$ & $25(43.86)$ & $36(37.50)$ & $61(39.87)$ \\
\hline & $\mathrm{Ff}$ & $3(5.26)$ & $9(9.38)$ & $12(7.84)$ \\
\hline & Total & $57(100)$ & $96(100)$ & $153(100)$ \\
\hline \multirow[t]{4}{*}{ TaqI } & $\mathrm{Tt}$ & $26(46.43)$ & $45(46.88)$ & $71(46.71) 0.685^{\mathrm{a}}$ \\
\hline & $\mathrm{TT}$ & 19.(33.93) & $37(38.54)$ & $56(36.84)$ \\
\hline & $\mathrm{tt}$ & $11(19.64)$ & $14(14.58)$ & $25(16.45)$ \\
\hline & Total & $56(100)$ & 96 (100) & $152(100)$ \\
\hline
\end{tabular}

Each VDR gene and its genotypes was as follows; ApaI (AA, Aa, and $a a), \operatorname{BsmI}(B B, B b$, and $b b), E c o R V(E E, E e$, and $e e), F o k I(F F, F f$, and $f f$ ), and TaqI (TT, Tt, and $t$ ). According to the sex, the frequency of each genotype was presented as a number (\%) in the frequency columns.; $P$ Value $<0.05$ is bolded and assumed as significant

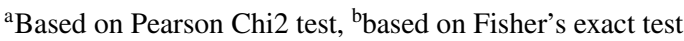

for the difference between our results and those from the 2013 analysis. Although osteoporosis was significantly more common in women than men, the LBDOO was significantly more frequent in men than women (Table 1). We attribute it to the slight difference in the distribution of age groups in participants of the two genders. Although the mean age of the two groups is not significantly different from each other, the frequency of the elderly is higher in men than in women $(P=0.055)$.

Our results show that $81.29 \%$ of T2D participants suffered from vitamin $D$ deficiency and, there is no significant difference between the two genders in this respect (Table 1). The results are in agreement with previously reported data that $82.2 \%$ of patients with T2D were suffering from vitamin D deficiency [41]. Iran is a country with elevated rates of long-term sunshine duration, this especially includes the cities of Sanandaj which even in the autumn has extended sunny days [42]. It seems that despite a high rate of longterm sunshine duration in Iran [42], there still exists a serious problem with vitamin D deficiency among the Iranian population, especially in diabetic patients [41].
In our study, there was no significant difference between the two genders in the frequency of the VDR gene's polymorphism in participants with T2D (Table 2). Unlike other studies [43, 44], we found no important association between low bone density (LBD/osteopenia/osteoporosis) and ApaI and BsmI genotypes in individuals who seemed to be affected by T2D. However, we found a significant association between a variant of $E c o R V$ polymorphism and an elevated risk of LBDOO in women with T2D ( $E E$ vs $E e$; adjusted OR: 7.64; $\mathrm{CI}_{95 \%}: 2.03-28.72$ ). Although the significant association persisted after adjustment for age and BMI, it was not independent of BMI and age (Table 4). Interestingly, recently published data suggest that the $E c o R V$ polymorphism may have an impact on the incidence and severity of Multiple Sclerosis in women [45]. However, the EcoRV SNP has never been studied in connection with osteoporosis in patients with T2D, and this is the first study focused on this issue. The logistic analysis revealed the $f f$ variant played a protective role for the risk of osteoporosis in women with T2D (ff vs. $F F$; crude OR:0.13, $\mathrm{CI}_{95 \%}: 0.02-1.12$ ); however, the adjusted OR did not remain significant (Table 3 ). In this regard, a previous study performed on the general population of the city of Sanandaj participated in the third phase of the IMOS study demonstrated the $f f$ variant of the FokI gene plays a protective role for the risk of osteoporosis in postmenopausal women (ff vs. $F F$; adjusted OR:0.136, $\mathrm{CI}_{95 \%}$ : 0.023-0.810) [46]. Angel et al. recommended that the $f$ allele $(F f+f f)$, of the FokI gene, is a possible risk factor for T2D through its possible effects on increasing BMI and obesity. In this case, the lower rate of osteoporosis in people with the $f f$ variant seems reasonable [47]. It may be noteworthy that the investigation indicated African women with $F F$ genotype had higher bone loss [48]. Kurt et al. confirmed a similar relationship between $F F$ genotype and increased risk of lower bone density in Turkish postmenopausal women [49]. Moreover, our results indicated that the $t t$ TaqI variant had a weak protective role for $\mathrm{LBDOO}$ in women with $\mathrm{T} 2 \mathrm{D}$ ( $t t$ vs. TT; OR: 0.18; $\mathrm{CI}_{95 \%}: 0.03-0.97$ ). Likewise, Gnanaprakash et al. [10] showed that TaqI polymorphism protects the Asian Indian population against T2D, perhaps through influencing anthropometric and biochemical parameters. It may describe by the fact that the VDR TaqI affects mRNA stability, which may lead to changing biological functions of vitamin D [15].

Although many studies report the VDR gene as influential on bone mineral density [50-52], the association of the VDR gene and bone density has not been established in distinctive ethnic populations, and the results of various articles show dissimilar effects [15]. Some reasons may be responsible for such differences between the results of diverse publications. These include low sample sizes, disparate ethnicity/race of subjects, environmental factors, divergent combinations of the study population, such as 
Table 3 Association of the VDR gene's polymorphism (ApaI, BsmI, EcoRV, FokI, and TaqI) with LBDOO in both genders, according to BMI and age in participants with type 2 diabetes

\begin{tabular}{|c|c|c|c|c|}
\hline $\begin{array}{l}\text { LBDOO versus Normal } \\
\text { ApaI }\end{array}$ & $\begin{array}{l}\text { Men } \\
\text { AA versus Aa }\end{array}$ & $\begin{array}{l}\text { Women } \\
\text { AA versus Aa }\end{array}$ & $\begin{array}{l}\text { Men } \\
\text { aa versus Aa }\end{array}$ & $\begin{array}{l}\text { Women } \\
\text { aa versus } \mathrm{Aa}\end{array}$ \\
\hline Model 1 & $.63(.19,2.09)$ & $.85(.34,2.13)$ & $.71(.15,3.22)$ & $.70(.23,2.13)$ \\
\hline Model2 & $.69(.19,2.53)$ & $.61(.19,1.96)$ & $1.09(.19,6.21)$ & $.87(.22,3.47)$ \\
\hline BsmI & $B B$ versus $B b$ & $B B$ versus $B b$ & $\mathrm{bb}$ versus $\mathrm{Bb}$ & $\mathrm{bb}$ versus $\mathrm{Bb}$ \\
\hline Model 1 & $.72(.21,2.49)$ & $1.51(.63,3.63)$ & $.27(.02,3.24)$ & $2.13(.33,13.70)$ \\
\hline Model 2 & $.69(.18,2.66)$ & $.88(.29,2.68)$ & $.40(.03,5.78)$ & $.77(.09,6.27)$ \\
\hline EcoRV & EE versus Ee & EE versus Ee & ee versus Ee & ee versus Ee \\
\hline Model 1 & $1.27(.40,4.02)$ & $3.52(1.39,8.87)^{* * * *}$ & $1.79(.29,11.13)$ & $1.25(.34,4.53)$ \\
\hline Model2 & $1.26(.36,4.41)$ & $7.64(2.03,28.72)^{* * * *}$ & $1.17(.17,8.07)$ & $.91(.16,5.11)$ \\
\hline FokI & Ff versus FF & Ff versus FF & ff versus FF & ff versus FF \\
\hline Model 1 & $1.09(.36,3.29)$ & $.98(.42,2.32)$ & $.31(.02,3.78)$ & $.13(.02,1.12)^{*}$ \\
\hline Model 2 & $.98(.29,3.23)$ & $.85(.29,2.47)$ & $.32(.02,4.76)$ & $.29(.03,2.81)$ \\
\hline TaqI & $\mathrm{TT}$ versus $\mathrm{Tt}$ & $\mathrm{TT}$ versus $\mathrm{Tt}$ & $\mathrm{tt}$ versus $\mathrm{Tt}$ & $\mathrm{tt}$ versus $\mathrm{Tt}$ \\
\hline Model 1 & $1.26(.37,4.23)$ & $1.41(.59,3.40)$ & $1.96(.42,9.11)$ & $.33(.08,1.34)$ \\
\hline Model 2 & $1.80(.46,6.95)$ & $.92(.30,2.84)$ & $2.63(.46,14.86)$ & $.18(.03, .97)^{* *}$ \\
\hline
\end{tabular}

LBDOO: "low bone density (LBD)/osteopenia/osteoporosis"; Applying logistic regression analysis, the correlation between the LBDOO status and VDR gene polymorphism was investigated. The most common haplotype was used as the reference for each type of VDR gene polymorphism. Each VDR gene and its genotypes was as follows; $A p a I(A A, A a$, and $a a), B s m I(B B, B b$, and $b b), E c o R V(E E, E e$, and $e e), F o k I(F F, F f$, and $f f$ ), and TaqI (TT, Tt, and $t t)$. Model 1: Crude model; Model 2:Adjusted for BMI and age; the data presented as $\mathrm{OR}\left(\mathrm{CI}_{95 \%}\right)$ and, significant relationship was bolded, $* P$ value is marginally significant $(<0.1)$, $* * P$ value is significant $(<0.05)$; ***P<0.01;****P<0.001

Table 4 Association of the VDR gene's polymorphism (ApaI, BsmI, EcoRV, FokI, and TaqI) with LBDOO in both genders, according to BMI and age in the T2D participants with $\mathrm{A} 1 \mathrm{C} \geq 6.4 \%$ and $\mathrm{FBS} \geq 3.9 \mathrm{mmol} / \mathrm{l}(126 \mathrm{mg} / \mathrm{dl})$

\begin{tabular}{|c|c|c|c|c|}
\hline $\begin{array}{l}\text { LBDOO versus normal } \\
\text { ApaI }\end{array}$ & $\begin{array}{l}\text { Men } \\
\text { AA versus Aa }\end{array}$ & $\begin{array}{l}\text { Women } \\
\text { AA versus Aa }\end{array}$ & $\begin{array}{l}\text { Men } \\
\text { aa versus Aa }\end{array}$ & $\begin{array}{l}\text { Women } \\
\text { aa versus Aa }\end{array}$ \\
\hline Model 1 & $.28(.02,3.52)$ & $.7(.17,2.91)$ & $1(\mathrm{NC})$ & $1(\mathrm{NC})$ \\
\hline Model2 & $.37(.02,6.00)$ & $.58(.09,3.49)$ & $1(\mathrm{NC})$ & $1(\mathrm{NC})$ \\
\hline BsmI & $\mathrm{BB}$ versus $\mathrm{Bb}$ & $B B$ versus $B b$ & $\mathrm{bb}$ versus $\mathrm{Bb}$ & $\mathrm{bb}$ versus $\mathrm{Bb}$ \\
\hline Model 1 & $1(\mathrm{NC})$ & $1.86(.46,7.48)$ & $1(\mathrm{NC})$ & $1.86(.10,34,44)$ \\
\hline Model 2 & $1(\mathrm{NC})$ & $1.26(.21,7.60)$ & $1(\mathrm{NC})$ & $2.35(.11,49.00)$ \\
\hline FokI & Ff versus FF & Ff versus FF & ff versus FF & ff versus FF \\
\hline Model 1 & $8(.66,97.31)$ & $1.24(.31,4.93)$ & NA & $1(\mathrm{NC})$ \\
\hline Model2 & $15.86(.60,422.28)^{*}$ & $.53(.07,3.96)$ & NA & $1(\mathrm{NC})$ \\
\hline EcoRV & EE versus Ee & EE versus Ee & ee versus Ee & ee versus Ee \\
\hline Model 1 & $8(.58,110.27)$ & $5.04(1.13,22.50)^{* * * *}$ & $1(\mathrm{NC})$ & $.93(.08,11.18)$ \\
\hline Model2 & $3.63(.17,77.74)$ & $7.24(1.00,52.47)^{* * *}$ & $1(\mathrm{NC})$ & $.87(.05,16.29)$ \\
\hline TaqI & $\mathrm{TT}$ versus $\mathrm{Tt}$ & $\mathrm{TT}$ versus $\mathrm{Tt}$ & $\mathrm{tt}$ versus $\mathrm{Tt}$ & $\mathrm{tt}$ versus $\mathrm{Tt}$ \\
\hline Model 1 & $1(\mathrm{NC})$ & $1.8(.41,7.81)$ & $.6(.03,13.58)$ & $.72(.10,5.17)$ \\
\hline Model2 & $1(\mathrm{NC})$ & $1.19(.17,8.24)$ & $1.75(.04,75.19)$ & $.34(.03,3.77)$ \\
\hline
\end{tabular}

LBDOO: "low bone density (LBD)/osteopenia/osteoporosis"; Applying logistic regression analysis, the correlation between the LBDOO status and VDR gene polymorphism was investigated. The most common haplotype was used as the reference for each type of VDR gene polymorphism. Each VDR gene and its genotypes was as follows; ApaI ( $A A, A a$, and $a a), B s m I$ ( $B B, B b$, and $b b), E c o R V$ ( $E E, E e$, and $e e$ ), FokI ( $F F$, $F f$ and $f f$ ), and TaqI (TT, Tt, and $t t)$; Model 1: Crude model; Model 2:Adjusted for BMI and age; the data is presented as OR $\left(\mathrm{CI}_{95 \%}\right)$ and, a significant relationship is bolded, $* P$ value is marginally significant $(<0.1), * * P$ value is significant $(<0.05)$; $* * * P<0.01 ; * * * * P<0.001, \mathrm{NC}$ : not calculated due to empty cells; NA: data not available due to empty cells 
unlike type of diabetes, the dissimilar mean duration of diabetes and, unlike a participant's mean and duration of age, and any other factors that may mask/exaggerate the genetic effect.

To detect T2D participants, an approximate approach was used and the use of oral/insulin hypoglycaemic agents was considered as a criterion for the diagnosis of diabetes that can lead to overestimation of diabetes. The diabetes duration variable was also not included in the original questionnaire. We had a small sample size as well as multiple potential predictors of a categorical nature to investigate. To avoid limiting the power of this exploratory analysis and to preserve the number of tables in the authorized range of journals, we did not divide the participants into the sex-age subgroups. We have considered these points in our next articles that include further confirmatory analyses; each article studies the association between the occurrence of osteoporosis and one of the studied polymorphisms according to having/ does not have T2D in four standard age-sex groups. The results of this study should be seen within the limits of a cross-sectional design. However, it should be stressed that the IMOS study was a national, population-based study that study of its data could provide valuable information on the occurrence of diseases/disorders and the factors affecting them with general details.

\section{Conclusion}

Vitamin D deficiency and osteoporosis were highly prevalent among patients with T2D aged $\geq 26$, who lived in Sanandaj, Iran. A TaqI variant had a weak protective role for LBDOO in women with T2D. Moreover, a strong positive association was found between a variant of $E c o R V$ polymorphism and the risk of LBDOO only in women with T2D. It is the first time that a study highlighted an association between EcoRV gene polymorphism and decreased bone density in individuals with type 2 diabetes; we believe that this study would serve as a base for future studies. Ethnicity-based cohort studies with a large number of T2D participants are highly recommended.

Acknowledgements The authors of this article consider it their duty to thank the staff of the Sanandaj health network, the participants, and all the EMRI staff who contributed to conducting the IMOS studies.

\section{Declarations}

Conflict of interest All authors state that there is no conflict of interest.

\section{References}

1. Johnell O, Kanis JA. An estimate of the worldwide prevalence and disability associated with osteoporotic fractures. Osteoporos Int. 2006;17(12):1726-33. https://doi.org/10.1007/ s00198-006-0172-4.

2. Nair R, Maseeh A. Vitamin D: the "sunshine" vitamin. J Pharmacol Pharmacother. 2012;3(2):118.

3. Azimi-Nezhad M, Ghayour-Mobarhan M, Parizadeh MR, et al. Prevalence of type 2 diabetes mellitus in Iran and its relationship with gender, urbanisation, education, marital status and occupation. Singapore Med J. 2008;49(7):571-6.

4. Mohammadi Z, Keshtkar A, Fayyazbakhsh F, et al. Prevalence of osteoporosis and vitamin D receptor gene polymorphisms (FokI) in an Iranian general population based study (Kurdistan) (IMOS). Med J Islam Repub Iran. 2015;29:238.

5. Leidig-Bruckner G, Grobholz S, Bruckner T, et al. Prevalence and determinants of osteoporosis in patients with type 1 and type 2 diabetes mellitus. BMC Endocr Disord. 2014;14(1):33. https:// doi.org/10.1186/1472-6823-14-33.

6. Gutzwiller J-P, Richterich J-P, Stanga Z, et al. Osteoporosis, diabetes, and hypertension are major risk factors for mortality in older adults: an intermediate report on a prospective survey of 1467 community-dwelling elderly healthy pensioners in Switzerland. BMC Geriatr. 2018;18(1):115. https://doi.org/10.1186/ s12877-018-0809-0.

7. Bohinc B, Snyder JE. The effects of race, ethnicity, and underlying medical diseases on osteoporosis are still unguided territory for internists. Ann Intern Med. 2008;149(7):514-5. https://doi.org/10. 7326/0003-4819-149-7-200810070-00019 (author reply 515-516).

8. McCarthy MI. Genomics, type 2 diabetes, and obesity. N Engl J Med. 2010;363(24):2339-50. https://doi.org/10.1056/NEJMr a0906948.

9. Raje M, Botre C, Ashma R. Genetic epidemiology of osteoporosis across four microsatellite markers near the VDR gene. Int J Mol Epidemiol Genet. 2013;4(2):101-8.

10. Gnanaprakash V, Bodhini D, Kanthimathi S, et al. Association of Vitamin D receptor (TaqI, BsmI, and FokI) polymorphisms with prediabetes and Type 2 diabetes in Asian Indians. J Diabetol. 2019;10(1):29.

11. Peacock M. Vitamin D receptor gene alleles and osteoporosis: a contrasting view. J Bone Miner Res. 1995;10(9):1294-7. https:// doi.org/10.1002/jbmr.5650100904.

12. Ma X, Jing Y, Qin W, et al. Vitamin D receptor gene polymorphism and bone mineral density in patients with type 2 diabetes mellitus. Chin Med J. 2001;114(11):1213-5.

13. Morrison NA, Qi JC, Tokita A, et al. Prediction of bone density from vitamin D receptor alleles. Nature. 1994;367(6460):284-7. https://doi.org/10.1038/367284a0.

14. Morrison NA, Yeoman R, Kelly PJ, et al. Contribution of transacting factor alleles to normal physiological variability: vitamin $\mathrm{D}$ receptor gene polymorphism and circulating osteocalcin. Proc Natl Acad Sci USA. 1992;89(15):6665-9. https://doi.org/10.1073/ pnas.89.15.6665.

15. Zhang L, Yin X, Wang J, et al. Associations between VDR gene polymorphisms and osteoporosis risk and bone mineral density in postmenopausal women: a systematic review and meta-analysis. Sci Rep. 2018;8(1):981. https://doi.org/10.1038/ s41598-017-18670-7.

16. Al-Daghri NM, Al-Attas O, Alokail MS, et al. Vitamin D receptor gene polymorphisms and HLA DRB $1 * 04$ cosegregation in Saudi type 2 diabetes patients. J Immunol. 2012;188(3):1325-32. https:// doi.org/10.4049/jimmunol.1101954.

17. Chakhtoura M, Azar ST. The role of vitamin d deficiency in the incidence, progression, and complications of type 1 diabetes 
mellitus. Int J Endocrinol. 2013;2013: 148673. https://doi.org/ 10.1155/2013/148673.

18. Bachali S, Dasu K, Ramalingam K, et al. Vitamin d deficiency and insulin resistance in normal and type 2 diabetes subjects. Indian J Clin Biochem. 2013;28(1):74-8. https://doi.org/10.1007/ s12291-012-0239-2.

19. Song Y, Wang L, Pittas AG, et al. Blood 25-hydroxy vitamin D levels and incident type 2 diabetes: a meta-analysis of prospective studies. Diabetes Care. 2013;36(5):1422-8. https://doi.org/ $10.2337 / \mathrm{dc} 12-0962$.

20. Mitri J, Muraru MD, Pittas AG. Vitamin D and type 2 diabetes: a systematic review. Eur J Clin Nutr. 2011;65(9):1005-15. https:// doi.org/10.1038/ejen.2011.118.

21. Mitri J, Dawson-Hughes B, Hu FB, et al. Effects of vitamin D and calcium supplementation on pancreatic beta cell function, insulin sensitivity, and glycemia in adults at high risk of diabetes: the Calcium and Vitamin D for Diabetes Mellitus (CaDDM) randomized controlled trial. Am J Clin Nutr. 2011;94(2):486-94. https://doi. org/10.3945/ajen.111.011684.

22. Joergensen C, Hovind P, Schmedes A, et al. Vitamin D levels, microvascular complications, and mortality in type 1 diabetes. Diabetes Care. 2011;34(5):1081-5. https://doi.org/10.2337/ dc10-2459.

23. Joergensen C, Gall MA, Schmedes A, et al. Vitamin D levels and mortality in type 2 diabetes. Diabetes Care. 2010;33(10):2238-43. https://doi.org/10.2337/dc10-0582.

24. Ortlepp JR, Lauscher J, Hoffmann R, et al. The vitamin D receptor gene variant is associated with the prevalence of type 2 diabetes mellitus and coronary artery disease. Diabet Med. 2001;18(10):842-5. https://doi.org/10.1046/j.1464-5491.2001. 00585.x.

25. Neyestani TR, Djazayery A, Shab-Bidar S, et al. Vitamin D Receptor Fok-I polymorphism modulates diabetic host response to vitamin D intake: need for a nutrigenetic approach. Diabetes Care. 2013;36(3):550-6. https://doi.org/10.2337/dc12-0919.

26. Malik R, Farooq R, Mehta P, et al. Association of vitamin D receptor gene polymorphism in adults with type 2 diabetes in the Kashmir Valley. Can J Diabetes. 2017;42:251-6. https://doi.org/ 10.1016/j.jcjd.2017.06.003.

27. Zhong X, Du Y, Lei Y, et al. Effects of vitamin D receptor gene polymorphism and clinical characteristics on risk of diabetic retinopathy in Han Chinese type 2 diabetes patients. Gene. 2015;566(2):212-6. https://doi.org/10.1016/j.gene.2015.04.045.

28. Shab-Bidar S, Neyestani TR, Djazayery A. Vitamin D receptor gene polymorphisms, metabolic syndrome, and type 2 diabetes in Iranian subjects: no association with observed SNPs. Int J Vitam Nutr Res. 2016;86(1-2):71-80. https://doi.org/10.1024/03009831/a000270.

29. Malecki MT, Frey J, Moczulski D, et al. Vitamin D receptor gene polymorphisms and association with type 2 diabetes mellitus in a Polish population. Exp Clin Endocrinol Diabetes. 2003;111(8):505-9. https://doi.org/10.1055/s-2003-44711.

30. Keshtkar A, Khashayar P, Mohammadi Z, et al. A suggested prototype for assessing bone health. Arch Iran Med. 2015;18(7):411-5.

31. Demmer RT, Zuk AM, Rosenbaum M, et al. Prevalence of diagnosed and undiagnosed type 2 diabetes mellitus among US adolescents: results from the continuous NHANES, 1999-2010. Am J Epidemiol. 2013;178(7):1106-13. https://doi.org/10.1093/aje/ kwt088.

32. DeShields SC, Cunningham TD. Comparison of osteoporosis in US adults with type 1 and type 2 diabetes mellitus. J Endocrinol Invest. 2018;41(9):1051-60. https://doi.org/10.1007/ s40618-018-0828-x.

33. Comino EJ, Tran DT, Haas M, et al. Validating self-report of diabetes use by participants in the 45 and up study: a record linkage study. BMC Health Serv Res. 2013;13(1):481. https://doi.org/10. 1186/1472-6963-13-481.

34. Bonjour JP, Ammann P, Rizzoli R. Importance of preclinical studies in the development of drugs for treatment of osteoporosis: a review related to the 1998 WHO guidelines. Osteoporos Int. 1999;9(5):379-93. https://doi.org/10.1007/s001980050161.

35. Dimai HP. Use of dual-energy X-ray absorptiometry (DXA) for diagnosis and fracture risk assessment; WHO-criteria, T- and Z-score, and reference databases. Bone. 2017;104:39-43. https:// doi.org/10.1016/j.bone.2016.12.016.

36. Holick MF, Binkley NC, Bischoff-Ferrari HA, et al. Evaluation, treatment, and prevention of vitamin D deficiency: an Endocrine Society clinical practice guideline. J Clin Endocrinol Metab. 2011;96(7):1911-30. https://doi.org/10.1210/jc.2011-0385.

37. Lang TA, Altman DG. Basic statistical reporting for articles published in biomedical journals: the "statistical analyses and methods in the published literature" or the SAMPL guidelines. Int J Nurs Stud. 2015;52(1):5-9. https://doi.org/10.1016/j.ijnur stu.2014.09.006.

38. World Health Organization. Global report on diabetes. World Health Organization; 2016. https://apps.who.int/iris/handle/ 10665/204871. Accessed 15 Feb 2021.

39. Larejani B, Zahedi F. Epidemiology of diabetes mellitus in iran. Iran J Diabetes Lipid Disord. 2001;1(1):1-8.

40. Doosti Irani A, Poorolajal J, Khalilian A, et al. Prevalence of osteoporosis in Iran: a meta-analysis. J Res Med Sci. 2013;18(9):759-66.

41. Rahimi MA, Izadi N, Niromand E, et al. Comparison of serum level of 25-hydroxy vitamin $d$ in diabetic patients and healthy subjects. Med J Mashhad Univ Med Sci. 2016;59(2):97-105.

42. Rahimzadeh F, Pedram M, Kruk MC. An examination of the trends in sunshine hours over Iran. Meteorol Appl. 2014;21(2):309-15.

43. Jia F, Sun RF, Li QH, et al. Vitamin D receptor BsmI polymorphism and osteoporosis risk: a meta-analysis from 26 studies. Genet Test Mol Biomark. 2013;17(1):30-4. https://doi.org/10. 1089/gtmb.2012.0267.

44. Salamone LM, Ferrell R, Black DM, et al. The association between vitamin $\mathrm{D}$ receptor gene polymorphisms and bone mineral density at the spine, hip and whole-body in premenopausal women. Osteoporos Int. 1996;6(1):63-8. https://doi.org/10.1007/ BF01626540.

45. Křenek P, Benešová Y, Bienertová-Vašků J, et al. The impact of five VDR polymorphisms on multiple sclerosis risk and progression: a case-control and genotype-phenotype study. J Mol Neurosci. 2018;64(4):559-66.

46. Mohammadi Z, Fayyazbakhsh F, Ebrahimi M, et al. Association between vitamin $\mathrm{D}$ receptor gene polymorphisms (Fok1 and Bsm1) and osteoporosis: a systematic review. J Diabetes Metab Disord. 2014;13(1):98. https://doi.org/10.1186/ s40200-014-0098-x.

47. Angel B, Lera L, Marquez C, et al. The association of VDR polymorphisms and type 2 diabetes in older people living in community in Santiago de Chile. Nutr Diabetes. 2018;8(1):31. https://doi. org/10.1038/s41387-018-0038-9.

48. Candido FG, Bressan J. Vitamin D: link between osteoporosis, obesity, and diabetes? Int J Mol Sci. 2014;15(4):6569-91. https:// doi.org/10.3390/ijms15046569.

49. Kurt O, Yilmaz-Aydogan H, Uyar M, et al. Evaluation of ERalpha and VDR gene polymorphisms in relation to bone mineral density in Turkish postmenopausal women. Mol Biol Rep. 2012;39(6):6723-30. https://doi.org/10.1007/s11033-012-1496-0.

50. Wawrzyniak A, Krela-Kazmierczak I, Marcinkowska M, et al. Vitamin D receptor gene foki polymorphism and the efficacy of postmenopausal osteoporosis treatment with denosumab. Osteoporosis Int. 2018;29:S504-S504. 
51. An M, Song XB, Chen XY. Vitamin D receptor BsmI polymorphism may be associated with an decreased osteoporosis risk in South China. Cell Mol Biol. 2017;63(5):50-4. https://doi.org/10. 14715/cmb/2017.63.5.10.

52. Borjas-Fajardo L, Zambrano M, Fernandez E, et al. Analysis of Bsm I polymorphism of the vitamin D receptor (VDR) gene in
Venezuelan female patients living in the state of Zulia with osteoporosis. Invest Clin. 2003;44(4):275-82.

Publisher's note Springer Nature remains neutral with regard to jurisdictional claims in published maps and institutional affiliations.

\section{Authors and Affiliations}

\section{Maryam Ghodsi $^{1}$ (D) Abbas Ali Keshtkar ${ }^{2}$ (D) - Farideh Razi ${ }^{1}$ (D) Mahsa Mohammad Amoli ${ }^{3}$ (D) . Ensieh Nasli-Esfahani ${ }^{1}$ (D) Fariba Zarrabi ${ }^{4,5}$ (D) Patricia Khashayar ${ }^{6,7}$ D Alireza Khajavi $^{8}(\mathbb{D})$ Bagher Larijani $^{9}$ (D) Mohamad Reza Mohajeri-Tehrani ${ }^{9}$ iD}

\author{
Maryam Ghodsi \\ maryam.ghodsi@gmail.com \\ Abbas Ali Keshtkar \\ abkeshtkar@gmail.com \\ Farideh Razi \\ f-razi@tums.ac.ir \\ Mahsa Mohammad Amoli \\ amolimm@tums.ac.ir \\ Ensieh Nasli-Esfahani \\ n.nasli@yahoo.com \\ Fariba Zarrabi \\ fariba_zarrabi@yahoo.com \\ Patricia Khashayar \\ patricia.kh@gmail.com \\ Alireza Khajavi \\ alireza.khajavi.student@gmail.com \\ Bagher Larijani \\ emri@tums.ac.ir \\ 1 Diabetes Research Center (DRC), Endocrinology \\ and Metabolism Clinical Sciences Institute, Tehran \\ University of Medical Sciences, Tehran, Iran
}

2 Department of Health Sciences Education Development, School of Public Health (SPH), Tehran University of Medical Sciences (TUMS), Tehran, Iran

3 Metabolic Disorders Research Center (MDRC), Endocrinology and Metabolism Molecular-Cellular Sciences Institute, Tehran University of Medical Sciences (TUMS), Tehran, Iran

4 Present Address: Thrombosis Hemostasis Research Center, Tehran University of Medical Sciences, Tehran, Iran

5 Department of Biology, Science and Research Branch, Islamic Azad University, Tehran, Iran

6 Present Address: Center for Microsystem Technology, Imec and Ghent University, Zwijnaarde, Ghent, Belgium

7 Osteoporosis Research Center (ORC), Endocrinology and Metabolism Clinical Sciences Institute, Tehran University of Medical Sciences, Tehran, Iran

8 Student Research Committee, Prevention of Metabolic Disorders Research Center, Research Institute for Endocrine Sciences, Shahid Beheshti University of Medical Sciences, Tehran, Iran

9 Endocrinology and Metabolism Research Center (EMRC), Endocrinology and Metabolism Clinical Sciences Institute, Tehran University of Medical Sciences (TUMS), Tehran, Iran 